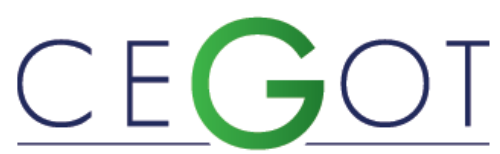

Centro de Estudos de Geografia e Ordenamento do Território
MENDES, MARESSA CORREA PEREIRA

Universidade Estadual Paulista

Faculdade de Arquitetura, Artes e Comunicação; Programa de Pós-Graduação em Arquitetura e Urbanismo

18.684-534, Lençóis Paulista, Brasil

maressa.mendes@unesp.br

FONTES, MARIA SOLANGE GURGEL DE CASTRO

Universidade Estadual Paulista

Faculdade de Arquitetura, Artes e Comunicação; Programa de Pós-Graduação

em Arquitetura e Urbanismo

17033-360, Bauru, Brasil

solange.fontes@unesp.br

FARIA, JOÃO ROBERTO GOMES DE

Universidade Estadual Paulista

Faculdade de Arquitetura, Artes e Comunicação; Programa de Pós-Graduação

em Arquitetura e Urbanismo

17033-360, Bauru, Brasil

joao.rg.faria@unesp.br

\title{
LEGISLAÇÕES URBANÍSTICAS DE INCENTIVO À SUSTENTABILIDADE: ESTUDOS EM MUNICÍPIOS
}

\section{PAULISTAS}

URBANISTIC LEGISLATION TO INCENTIVIZE SUSTAINABILITY: STUDIES OF THE SÃO PAULO MUNICIPALITIES

Referência: Mendes, Maressa Correa Pereira; Fontes, Maria Solange Gurgel de Castro; Faria, João Roberto Gomes de (2021). LEGISLAÇÕES URBANÍSTICAS DE INCENTIVO À SUSTENTABILIDADE: ESTUDOS EM MUNICÍPIOS PAULISTAS. Revista de Geografia e Ordenamento do Território (GOT), no 22 (Dezembro). Centro de Estudos de Geografia e Ordenamento do Território, p. 182 - 199, dx.doi.org/10.17127/got/2021.22.008

\section{RESUMO}

O presente trabalho trata de uma avaliação das legislações urbanísticas dos municípios paulistas de São Carlos (251.983 habitantes), Ribeirão Preto (703.293 habitantes) e Campinas (1.204.073 habitantes) com o intuito de: 1. Identificar a existência de políticas de incentivo à sustentabilidade urbana e 2. Compreender se as diferentes escalas territoriais e populacionais, desses municípios, influenciam na execução de políticas de sustentabilidade. Foi realizado levantamento bibliográfico de pesquisas acadêmicas para conhecer as discussões existentes sobre o tema, e, através da consulta aos Planos Diretores e suas legislações complementares, foram analisadas as possibilidades de construção de políticas de incentivo a edificações sustentáveis, tais como: utilização dos parâmetros de controle urbanístico e/ou da aplicação dos institutos Jurídicos e Políticos ou Tributários e Financeiros do Estatuto da Cidade, como a Outorga Onerosa do Direito de Construir e IPTU Verde, entre outras. Para os municípios avaliados, apesar de existir algumas legislações urbanísticas de incentivo a sustentabilidade, observou-se que há muito a avançar, neste sentido. 
Palavras-chave: Legislação urbanística; Sustentabilidade; Políticas de incentivo; Municípios paulistas.

\section{ABSTRACT}

The present study deals with an evaluation of the urbanistic legislation of the São Paulo municipalities of São Carlos (251,983 inhabitants), Ribeirão Preto (703,293 inhabitants) and Campinas $(1,204,073$ inhabitants) in order to: 1 . Identify the existence of any incentive policy for urban sustainability and 2. Understand whether the different territorial and population scales of these municipalities influence the implementation of sustainability policies. A bibliographic survey of academic research was carried out to learn about the existing discussions on the subject and possibilities of building policies to encourage sustainable buildings were analyzed by consulting the Master Plans and their complementary legislation, such as: use of urban control parameters and / or the application of the Legal and Political or Tax and Financial institutes of the City Statute, such as the Onerous Grant of the Right to Build, Green Property Tax, among others. Despite the existence of some urban legislation to encourage sustainability, it was observed that there is much to be done in this direction for the municipalities evaluated.

Keywords: Urbanistic legislation; Sustainability; Incentive policy; São Paulo municipalities.

\section{Introdução}

O crescimento acelerado das cidades brasileiras nos últimos anos introduziu nas discussões acerca das políticas públicas uma série de problemas e questões relacionadas com a gestão e o ordenamento do espaço urbano. O habitar a cidade requer uma relação de equilíbrio entre as funções urbanas de moradia, trabalho, lazer, locomoção com o ambiente natural. 0 desejado equilíbrio muitas vezes não é alcançada, em função da existência de permanente contradição entre a cidade formal, regida pelas normas urbanísticas que produz um espaço urbano regular com melhores condições de qualidade ambiental urbana, e a cidade informal produzida pela população de baixa renda, em áreas, cuja ocupação é legalmente restrita, tais como: áreas verdes protegidas, áreas de manancial, encostas, margem de rios e córregos, gerando situações de precariedade e situações de insustentabilidade (Júnior \& Rolnik, 2001).

O planejamento propunha uma cidade no papel, em condições de construção e produção arquitetônica pelo mercado, nas porções estruturadas das cidades, caracterizadas pela existência do conjunto de infraestrutura urbana (saneamento, abastecimento de água, esgotamento sanitário, pavimentação, drenagem, iluminação pública), como também pela 
proximidade do trabalho, do lazer e da oferta de atividades culturais e de entretenimento. No entanto, nas zonas marginais instaurou-se um processo de autoconstrução conduzido pela população de baixa renda que não tinha como se apropriar do espaço urbano regular. Nesse sentido, entende-se que a cidade formal oferece melhores condições de sustentabilidade do que a informal, contexto em que o termo é utilizado ao longo do trabalho.

A Constituição Federal (CF) de 1988 atribui aos Municípios a competência privativa de legislar sobre os interesses locais de seu território, na promoção do adequado ordenamento territorial através do planejamento e controle do uso, do parcelamento e da ocupação do solo urbano, sendo, conforme Art. 182 da CF, responsável pela promoção da política urbana, que tem como objetivo ordenar o pleno desenvolvimento das funções sociais da cidade e da propriedade urbana (Júnior \& Rolnik, 2001). Esta prerrogativa impôs um grande desafio para a gestão urbana municipal e a legislação urbanística se tornou o principal instrumento para seu enfrentamento.

Estabelecido o princípio da função social da cidade e da propriedade urbana, o Estatuto da Cidade (EC) é a ferramenta que direciona os princípios da política de uso e ocupação do solo, no intuito de promover a transformação dos espaços urbanos em cidades mais equânimes, democráticas e de bases sustentáveis, a partir da garantia dos direito à moradia, saneamento ambiental, infraestrutura urbana, transporte, trabalho e lazer (Feio, 2018), mediante definição de diretrizes gerais, das quais destaca-se o inciso XIX do Art. 2 ำ da Lei 10.257/2001 (EC):

Art. 2 A política urbana tem por objetivo ordenar o pleno desenvolvimento das funções sociais da cidade e da propriedade urbana, mediante as seguintes diretrizes gerais:

\section{$(\ldots)$}

XIX - garantia de condições condignas de acessibilidade, utilização e conforto nas dependências internas das edificações urbanas, inclusive nas destinadas à moradia (...), observados requisitos mínimos de dimensionamento, ventilação, iluminação, ergonomia, privacidade e qualidade dos materiais empregados. (Brasil, 2001) 
Assim, é com base nestes princípios que os municípios têm, ao longo dos anos, desenvolvido suas legislações urbanísticas, e estabelecido diretrizes que abarcam uma série de questões urbanas, que vão do ordenamento territorial e da proteção das áreas ambientais e de preservação permanente, a políticas sociais e de mobilidade urbana, sob a premissa que a sintonia entre estas políticas auxiliam na construção de cidades mais sustentáveis.

Nesse contexto, este trabalho propõe avaliar as legislações urbanísticas de três municípios de diferentes portes do estado de São Paulo: São Carlos (251.983 habitantes), Ribeirão Preto (703.293 habitantes) e Campinas (1.204.073 habitantes), com o intuito de: 1 . identificar a existência de políticas de incentivo à sustentabilidade urbana e 2. compreender se as diferentes escalas territoriais e populacionais, desses municípios, influenciam na execução de políticas de sustentabilidade.

Para isso, e com o fim de reconhecer os diferentes meios de aplicação das políticas de incentivo, dentre eles, utilização dos parâmetros de controle urbanístico e/ou aplicação dos institutos Jurídicos e Políticos ou Tributários e Financeiros do Estatuto da Cidade, foram avaliados os Planos Diretores, as Leis de parcelamento, uso e ocupação do solo e, a existência ou não de legislações complementares de incentivo a aplicação de Imposto Predial e Territorial Urbano (IPTU) Verde ou outros modelos de certificação.

Ressalta-se que a regulamentação de institutos tributários e financeiros, aqui representada pelo IPTU Verde, tem sido um dos caminhos mais diretos para a construção de políticas de incentivo a sustentabilidade, devido à possibilidade de maior abrangência de sua aplicabilidade, tornando-se uma importante ferramenta para o tema.

\section{Materiais e métodos}

Para identificar trabalhos relacionados ao tema, foi realizada uma busca na base de dados da Biblioteca Digital Brasileira de Dissertações e Teses com as seguintes relações de palavras chaves: Plano Diretor e Sustentabilidade; Plano Diretor e Edificações Sustentáveis; Legislação Urbana e Edificações Sustentáveis; Legislação Urbana e Sustentabilidade; Edificações Sustentáveis; e IPTU Verde. 
O resultado desse levantamento bibliográfico demonstrou que esse tema ainda é pouco presente nas pesquisas acadêmicas, mas destacam-se os estudos relativos ao IPTU Verde (Azevedo, 2017; Dantas, 2014; Feio, 2018), que se trata de uma das políticas de incentivo a edificações sustentáveis mais difundidas entre os Municípios. Entretanto, para este trabalho se propôs, para além do uso do IPTU Verde, a identificação de outros instrumentos, tais como: a utilização dos parâmetros de controle urbanístico e/ou a aplicação dos institutos Jurídicos e Políticos ou Tributários e Financeiros do Estatuto da Cidade, como forma de incentivar a sustentabilidade edilícia, a partir de pesquisa em literatura específica ou em modelos adotados por outros municípios.

Para a seleção dos Municípios, cuja legislação urbanística seria avaliada, adotou-se como critério a diferença de porte entre eles, ao considerar o seguinte recorte populacional: um município de médio porte com população entre 100 mil e 500 mil habitantes, um com população entre 500 mil e 1 milhão de habitantes e, por fim, um município de maior porte com população a partir de 1 milhão de habitantes, bem como seu papel na hierarquia urbana. Para auxiliar nesta seleção foi considerada a metodologia adotada pelo IBGE (2008) na construção da hierarquia dos centros urbanos, que classifica as cidades em cinco níveis: Metrópoles, Capital Regional, Centro Sub-Regional, Centro de Zona e Centro Local. Foi considerada, ainda, a localização geográfica dos municípios, ou seja, todos localizados no interior do estado de São Paulo, o que repercute nas características físicas de seu território e nas semelhanças quanto ao modelo de ocupação.

Com base nestes parâmetros foram selecionados os Municípios de São Carlos (251.983 habitantes), classificado como Centro Sub-Regional A ${ }^{1}$ e Ribeirão Preto (703.293 habitantes) e Campinas (1.204.073 habitantes), classificados como Capitais Regionais $\mathrm{A}^{2}$, de acordo com os critérios do IBGE (2008). Entretanto, estudo desenvolvido pelo Observatório das Metrópoles, dedicado à avaliação de metodologias de hierarquização urbana e tipologia das

\footnotetext{
${ }^{1}$ Segundo IBGE (2008) Centro sub-regional são centros urbanos com atividades de gestão menos complexas, área de atuação mais reduzida, e quanto aos relacionamentos com centros externos à sua própria rede estes ocorrem, em geral, apenas com as três metrópoles nacionais. O Centro sub-regional A é uma de suas classificações caracterizado por apresentar em média 95 mil habitantes e 112 relacionamentos.

${ }^{2}$ As Capitais Regionais, de acordo com IBGE (2008) de forma semelhante às metrópoles se relacionam com estrato superior da rede urbana, e possuem um nível de capacidade de gestão imediatamente inferior aos das metrópoles, apresentam área de influência de âmbito regional e se configuram como destino no atendimento de um conjunto de atividades por um grande número de municípios. A Capital Regional A é caracterizada por uma média populacional de 955 mi habitantes e 487 relacionamentos.
} 
cidades Brasileiras, classificou Campinas como Metrópole Regional (Bitoun \& Miranda, 2009), em função da sua posição estratégica e agregadora de atividades no estado. Atualmente, o município é autarquia responsável pela integração, organização, planejamento e execução das funções públicas de interesse da Região Metropolitana de Campinas.

A adoção desta classificação permite avaliar um Centro Sub-Regional, São Carlos; uma Capital Regional, Ribeirão Preto, e, por fim, uma Metrópole Regional, Campinas, para compreender se as diferentes escalas territoriais e populacionais influenciam na execução de políticas de sustentabilidade. Essas políticas são voltadas aos diferentes desafios enfrentados pelos órgãos de gestão urbana destes municípios, em função do maior ou menor enfrentamento de problemas e conflitos urbanos, que ameaçam a garantia dos direitos fundamentais dos cidadãos, indispensáveis para a construção de cidades sustentáveis.

Após a seleção dos municípios foi realizada pesquisa nos sites oficiais das Prefeituras Municipais, Câmaras Municipais e no site https://leismunicipais.com.br/, para levantamento de suas respectivas legislações urbanísticas. Além disso, outras normas, artigos e documentos foram consultados para identificar experiências de aplicação de políticas de incentivo à construção de edificações sustentáveis, em outros municípios, que se constituíssem como exemplos e referências para a presente análise.

\section{Resultados}

As principais legislações urbanísticas municipais que podem contribuir como política de enfrentamento à sustentabilidade são: os Planos Diretores (PD), as leis de parcelamento, uso e ocupação do solo e, quando houver, legislações complementares de incentivo a aplicação de IPTU Verde ou outros modelos de certificação. Estas leis se relacionam em um contexto de hierarquia e complementaridade.

O Plano Diretor tem o papel de definir as medidas macro da política urbana, integrando diferentes temas: habitação, mobilidade, meio ambiente, saneamento, drenagem, paisagem, cultura, proteção do patrimônio histórico, dentre outros, de forma conciliativa na busca do desenvolvimento econômico-social com preservação e proteção ambiental (Schweigert, 2006). 
As leis de Parcelamento do solo e Zoneamento, uso e ocupação do solo são responsáveis pelo ordenamento territorial, observando os objetivos e diretrizes do Plano Diretor. A lei de Parcelamento do solo produz a forma urbana através de parâmetros definidores do traçado urbano, dimensões de lotes, porcentagens de áreas verdes e áreas insitucionais. A Lei de Zoneamento, uso e ocupação do solo dispõe quanto a distribuição dos usos nas cidades, o modelo tipológico construtivo e os parâmetros a serem atendidos pelas edificações, ambas, consideram os valores ambientais de cada localidade, tais como a existência de áreas de preservação permanente - APP, áreas de proteção ambiental, mata, rios, córregos, nascentes, dentre outro. São nos regramentos desta norma que se encontram amplas possibilidades de implementação de políticas de incentivo à sustentabilidade edilícia.

As leis complementares relacionadas ao programa IPTU Verde e certificações são específicas na construção de políticas de incentivo a sustentabilidade. Segundo Feio (2018), o IPTU Verde se configura como uma política pública que tem o intuito de autorizar concessão de isenção fiscal para os contribuintes que se comprometem a auxiliar o poder público na proteção do meio ambiente e na promoção do bem-estar social. Isso pode ser feito na implementação de ações voltadas para a preservação de áreas verdes, realização de coleta seletiva, captação de energia solar e reutilização de águas de chuva, entre outras ações.

As certificações ambientais, na avaliação de Gaspar (2018, p. 31), "são atestados de cumprimento de pré-requisitos que garantem menor impacto ambiental e o menor consumo de energia". Um de seus objetivos é a promoção de conscientização no processo construtivo da edificação, para além da aplicação dos requisitos mínimos, mas da compreensão dos impactos positivos destas medidas na promoção e construção de cidades, espaços e edificações sustentáveis, e os benefícios desta política para a presente e futura gerações.

Entendidos os objetivos e as funções das normas, objeto deste estudo, foram identificadas possibilidades de uso de instrumentos que compõem a legislação urbanística, tais como: parâmetros de controle urbanístico e/ou institutos Jurídicos e Políticos ou Tributários e Financeiros do Estatuto da Cidade, que podem ser aprimorados para a produção de edificações mais sustentáveis. Com base nestes exemplos, avaliou-se o uso destes modelos de políticas de sustentabilidade ou similares, nos respectivos municípios, a partir da análise das legislações listadas na tabela 1. 
Tabela 1 - Legislações urbanísticas avaliadas por cidade

\begin{tabular}{|c|c|c|}
\hline MUNICIPIO & NORMA & DESCRIÇÃO \\
\hline \multirow{4}{*}{ São Carlos } & Lei $18.053 / 2016$ & Plano Diretor \\
\hline & Lei 13.692/2005 & Define critérios para lançamento do IPTU \\
\hline & Derroto 261/200e & Regulamentação dos incentivos ambientais da lei \\
\hline & & $13.692 / 2005$ \\
\hline \multirow{3}{*}{$\begin{array}{l}\text { Ribeirão } \\
\text { Preto }\end{array}$} & Lei comp. 2.866/2018 & Plano Diretor \\
\hline & Lei comp. 2.157/2007 & Lei de parcelamento, uso e ocupação do solo \\
\hline & Lei comp. 2.996/2019 & $\begin{array}{l}\text { Institui a concessão de benefício tributário por adoção de } \\
\text { ações ecológicas - IPTU Verde }\end{array}$ \\
\hline \multirow{4}{*}{ Campinas } & Lei comp. 189/2018 & Plano Diretor Estratégico \\
\hline & Lei comp. 208/2018 & Lei de parcelamento, ocupação e uso do solo \\
\hline & Lei comp. 49/2013 & $\begin{array}{l}\text { Licenciamento e controle ambiental de empreendimentos } \\
\text { e atividades }\end{array}$ \\
\hline & Decreto $18.705 / 2015$ & Regulamenta os procedimentos da Lei comp. 49/2013 \\
\hline
\end{tabular}

\subsection{Parâmetros de controle urbanístico}

Os parâmetros de controle urbanísticos são o conjunto de regramentos que devem ser observados no momento de elaboração do projeto arquitetônico de uma edificação. São responsáveis por estabelecer um modelo de ocupação dos lotes e, dentro do planejamento dos municípios, induzir o adensamento, incentivar a verticalização e qualificar a ambiência urbana através de exigências relativas a recuos, previsão de áreas verdes e permeáveis nos terrenos e da compatibilização da altura das edificações com o entorno. Alguns exemplos de parâmetros de controle urbanísticos presentes nas legislações urbanísticas são: coeficiente de aproveitamento, taxa de ocupação ou área ocupada do lote, taxa de permeabilidade ou área permeável, lote mínimo e área mínima, gabarito e altura máxima da edificação, e recuos ou afastamentos. 
A tabela 2 apresenta a aplicação nos municípios de Belo Horizonte (MG), São Paulo (SP) e Vitória (ES) dos parâmetros de controle urbanísticos como política de incentivo a sustentabilidade, demonstrando o uso das legislações urbanísticas para estabelecer práticas sustentáveis a partir de parâmetros rotineiramente aplicados pela maior parte das normas urbanísticas, ou, até mesmo, através do aprimoramento ou definição de novos parâmetros.

Observa-se que os parâmetros que guardam maior relação com medidas de sustentabilidade edilícia, com reflexo no ambiente urbano são: a taxa de permeabilidade e os recuos ou afastamentos. A taxa de permeabilidade tem relação com a capacidade drenante do solo a partir do controle de impermeabilização. Tal parâmetro, quando complementado com a exigência de cobertura vegetal, pode influenciar os microclimas do entorno das edificações. Os recuos ou afastamentos, quando relacionados com a altura da edificação, através da previsão da ampliação progressiva do recuo à medida que a edificação se verticaliza, podem resultar em melhorias significativas na ventilação e iluminação dos ambientes internos da edificação, bem como reduzir os impactos de sombreamento na vizinhança imediata.

Destaca-se a inovação da legislação do município de São Paulo com a criação da Quota Ambiental, que alia taxa de permeabilidade a critérios de sustentabilidade na promoção de qualificação ambiental dos lotes urbanos e seu entorno.

Em relação às legislações urbanísticas dos municípios avaliados, foram observadas algumas iniciativas de implementar medidas de sustentabilidade, que são apresentadas na tabela 3.

Nota-se que os incentivos adotados pelos municípios de São Carlos, Ribeirão Preto e Campinas em muito se assemelham aos exemplos apontados na tabela 2, caracterizados como aprimoramentos dos parâmetros já difundidos na legislação urbanística. Destaca-se a exigência de áreas verdes nos loteamentos e a preocupação com a conectividade destas, presente nas legislações de Ribeirão Preto e Campinas, a exigência de áreas ajardinadas nos condomínios residenciais, previsto em São Carlos e Ribeirão Preto, e o Coeficiente de Cobertura Vegetal (CCV) estabelecido na legislação de São Carlos. 
Tabela 2 - Parâmetros de controle urbanístico aplicados como política de incentivo à sustentabilidade

\begin{tabular}{|c|c|c|}
\hline MUNIC & LEI & PARÂMETROS \\
\hline Horizonte & $\begin{array}{l}\text { Lei no } 7.166 \text { de } \\
1996 \\
\text { Parcelamento, } \\
\text { uso e ocupação } \\
\text { do solo }\end{array}$ & $\begin{array}{l}\text { Afastamentos laterais e de fundos: define regra de } \\
\text { escalonamento, quanto maior a altura da edificação maior será o } \\
\text { afastamento, objetiva melhorar a ventilação e iluminação dos } \\
\text { compartimentos da edificação. } \\
\text { Taxa de permeabilidade: define como área descoberta e } \\
\text { permeável do terreno dotada de vegetação, contribuindo para o } \\
\text { equilíbrio climático. Incentiva a manutenção de área permeável } \\
\text { livre e vegetada no afastamento frontal da edificação, através da } \\
\text { conversão desta área em pagamento do potencial construtivo } \\
\text { adicional utilizado no próprio lote. }\end{array}$ \\
\hline São Paulo & $\begin{array}{l}\text { Lei no } 16.402 \\
\text { de } 2016 \\
\text { Parcelamento, } \\
\text { uso e ocupação } \\
\text { do solo }\end{array}$ & $\begin{array}{l}\text { Quota Ambiental: define um conjunto de regras de ocupação dos } \\
\text { lotes que objetivam qualificá-los ambientalmente, cada } \\
\text { construção deve alcançar determinada pontuação, a partir da } \\
\text { aplicação de indicadores de cobertura vegetal (CV) e drenagem } \\
\text { (D), exemplos: cobertura verde, fachada/ muro verde, plantio de } \\
\text { vegetação, área ajardinada, piso poroso ou semipermeável, } \\
\text { reservatório de retenção. }\end{array}$ \\
\hline Vitória & $\begin{array}{l}\text { Lei no } 9.271 \text { de } \\
2018 \\
\text { Plano Diretor } \\
\text { Urbano }\end{array}$ & $\begin{array}{l}\text { Afastamentos laterais e de fundos: define regra de } \\
\text { escalonamento, sendo que quanto maior a altura da edificação } \\
\text { maior será o afastamento aplicado, podendo ser este aplicado } \\
\text { agrupado ou por pavimento, objetiva melhorias na ventilação e } \\
\text { iluminação dos compartimentos da edificação. } \\
\text { Taxa de permeabilidade: exige que metade da área permeável do } \\
\text { lote possua cobertura vegetal, com o objetivo de melhorar a } \\
\text { ambiência urbana. } \\
\text { Plantio de árvores: regulamenta a obrigatoriedade de plantio de } \\
\text { árvores em áreas de estacionamento descoberto de grandes } \\
\text { empreendimentos, com o intuito de melhorar a ambiência e o } \\
\text { microclima do entorno destas edificações. }\end{array}$ \\
\hline
\end{tabular}


Tabela 3 - Parâmetros de controle urbanístico na legislação dos municípios avaliados

\begin{tabular}{|c|c|c|}
\hline MUNICÍPIO & LEI & PARÂMETROS \\
\hline São Carlos & Plano Diretor & $\begin{array}{l}\text { Coeficiente de cobertura vegetal (CCV): os imóveis localizados nas } \\
\text { áreas destinadas à proteção, regulação e ocupação restritas e } \\
\text { controlada, devem prever porcentagem de seus terrenos, entre } 10 \% \\
\text { a } 50 \% \text {, cobertas por vegetação arbórea e arbustiva. } \\
\text { Faixa ajardinada: condomínios de maior porte devem prever } \\
\text { calçadas com faixa ajardinada. }\end{array}$ \\
\hline Ribeirão & $\begin{array}{l}\text { Parcelamento, } \\
\text { uso e ocupação } \\
\text { do solo }\end{array}$ & $\begin{array}{l}\text { Taxa de solo natural: exige a manutenção de } 10 \% \text { da área do lote } \\
\text { permeável e com cobertura vegetal. } \\
\text { Reserva de áreas verdes em torno de } 20 \% \text { a } 35 \% \text { nos novos } \\
\text { loteamentos com recuperação, plantio ou manutenção de } \\
\text { vegetação de espécies arbóreas nativas, observando conectividade } \\
\text { com outras áreas verdes; e no caso de condomínios exigência de } \\
\text { arborização e implantação de } 1 \mathrm{~m}^{2} \text { de área de jardim por unidade. } \\
\text { Afastamentos e recuos: ampliação progressiva dos afastamentos } \\
\text { para edificações acima do gabarito básico de } 10 \mathrm{~m} \text { de altura. }\end{array}$ \\
\hline Campinas & $\begin{array}{l}\text { Parcelamento, } \\
\text { uso e ocupação } \\
\text { do solo }\end{array}$ & $\begin{array}{l}\text { Reserva de áreas verdes em torno de } 20 \% \text { nos novos loteamentos } \\
\text { com recuperação, plantio ou manutenção de vegetação de espécies } \\
\text { arbóreas nativas, observando conectividade com outras áreas } \\
\text { verdes. } \\
\text { Afastamentos e recuos: ampliação progressiva dos afastamentos } \\
\text { com critérios diferentes com relação aos afastamentos de fundo e } \\
\text { laterais, para edificações acima do gabarito básico de } 10 \mathrm{~m} \text { de altura. }\end{array}$ \\
\hline
\end{tabular}

\subsection{Instituto Jurídico e Político do Estatuto da Cidade}

Os Institutos Jurídicos e Políticos do Estatuto da Cidade foram definidos no inciso V do Art. 4으 da Lei $10.257 / 2001$, e têm como desafio a proposição de políticas capazes de contornar as contradições urbanas ocasionadas pelo processo de crescimento desigual das cidades, a partir da aplicação individual ou em conjunto, no intuito de fazer cumprir os princípios da função social da cidade e da propriedade urbana. 
Para este trabalho foi considerado o instrumento da Outorga Onerosa do Direito de Construir (OODC), que trata do exercício do direito de construir acima do coeficiente de aproveitamento básico, adotado em legislação municipal, mediante contrapartida financeira a ser prestada pelo beneficiário. A tabela 4 mostra os incentivos de aplicação desses instrumentos nas cidades de Belo Horizonte (MG), Salvador (BA) e Vitória (ES).

Verifica-se que, a partir da fundamentação do instrumento, é possível instituir políticas de incentivo à sustentabilidade, através da definição de isenção ou redução do valor da contrapartida financeira considerando o uso de critérios de sustentabilidade nas edificações, ou até mesmo, a partir de um modelo de pontuação, com a contabilização do potencial adicional, conforme exemplos sistematizados na tabela 4.

Quanto às legislações urbanísticas não foi observado, nos municípios estudados, o uso da Outorga Onerosa do Direito de Construir para implementar ações de incentivo à sustentabilidade, tampouco de outro instrumento jurídico e político do EC. Essa constatação indica uma possibilidade de aprimorar aquelas legislações no sentido de ampliar as políticas de incentivo a sustentabilidade ao nível municipal, a partir da aplicação destes instrumentos.

Tabela 4 - Aplicação da Outorga Onerosa do Direito de Construir como política de incentivo à sustentabilidade

\begin{tabular}{l|l|l}
\hline MUNICÍPIO & LEI & OODC \\
\hline $\begin{array}{l}\text { Belo } \\
\text { Horizonte }\end{array}$ & $\begin{array}{l}\text { Lei no 7.166 de } \\
1996 \\
\text { Parcelamento, } \\
\text { uso e ocupação } \\
\text { do solo }\end{array}$ & $\begin{array}{l}\text { O proprietário de imóvel que implantar área permeável, livre e } \\
\text { com cobertura vegetal no afastamento frontal de sua edificação, } \\
\text { poderá adquirir potencial adicional de construção para o mesmo } \\
\text { lote, acima do básico, tendo como contrapartida a aplicação da } \\
\text { referida ação sustentável. }\end{array}$ \\
\hline Salvador & $\begin{array}{l}\text { Lei no 9.096 de } \\
2016 \\
\text { Plano Diretor de } \\
\text { Desenvolvimento } \\
\text { Urbano }\end{array}$ & $\begin{array}{l}\text { Institui fator de redução da contrapartida financeira da OODC para } \\
\text { empreendimentos que obtiverem, na sua fase de licenciamento, a } \\
\text { certificação concedida pelo IPTU Verde, que prevê desconto na } \\
\text { alíquota mediante previsão de medidas de sustentabilidade na } \\
\text { construção das edificações. }\end{array}$ \\
\hline Vitória & $\begin{array}{l}\text { Lei no 9.271 de } \\
2018 \\
\text { Plano Diretor } \\
\text { Urbano }\end{array}$ & $\begin{array}{l}\text { Prevê acréscimo de potencial construtivo acima do coeficiente } \\
\text { básico, instituído para a Zona do Parque Tecnológico, para } \\
\text { edificações que apresentem cobertura de telhado verde; taxa de } \\
\text { permeabilidade acima do mínimo exigido pela Lei; e uso de meios } \\
\text { renováveis para geração de energia e aquecimento de água, sendo } \\
\text { definido um valor máximo de acréscimo por critério atendido. }\end{array}$ \\
\hline
\end{tabular}




\subsection{Institutos Tributários e Financeiros do Estatuto da Cidade}

Ainda dentro do instrumental previsto no Estatuto da Cidade, para construção de uma política urbana dentro dos princípios constitucionais de função social da cidade e da propriedade, o inciso $\mathrm{V}$ de seu artigo 4ํㅡㄹ , dispõe sobre os institutos tributários e financeiros, dentre eles o Imposto sobre a propriedade predial e territorial urbana - IPTU, que conforme artigo $32 \mathrm{da}$ Lei 5.172/1966 - Código Tributário Nacional, trata-se de:

(...) imposto, de competência dos Municípios, sobre a propriedade predial e territorial urbana tem como fato gerador a propriedade, o domínio útil ou a posse de bem imóvel por natureza ou por acessão física, como definido na lei civil, localizado na zona urbana do Município. (Brasil, 1966)

Por se tratar de imposto de competência dos Municípios, tem sido crescente, nos últimos anos, sua aplicação como ferramenta indutora de práticas sustentáveis nas cidades sob a denominação de IPTU Verde. Segundo Feio (2018) o IPTU Verde se caracteriza como uma política pública de concessão de isenção fiscal, aos proprietários de imóveis urbanos que auxiliarem a administração pública municipal na proteção do meio ambiente e promoção do bem-estar social. Esta política possibilita o estímulo à execução de pequenas ações em prol do meio ambiente como: manter cobertura vegetal, cultivar árvores nas calçadas ou em seu imóvel, adotar áreas verdes, utilizar tecnologias sustentáveis, dentre outros.

Para exemplificar o instrumento, utilizou-se a experiência do IPTU Verde de Salvador, instituído como um Programa de Certificação Sustentável, com "objetivo de incentivar empreendimentos que contemplem ações e práticas sustentáveis destinadas a redução do consumo de recursos naturais e dos impactos ambientais" (Salvador, 2015. p.1). Esse instrumento é aplicável às novas construções, nas ampliações e/ou reforma das já existentes, para todos os usos. Um anexo do Decreto no. 25.899/2015 apresenta a indicação das práticas de sustentabilidade e a pontuação atribuída a cada uma delas. À medida que se atende determinado critério ele é pontuado, e com base no somatório da pontuação é feita a classificação em Bronze, Prata e Ouro; assim, cada categoria faz jus a uma porcentagem de desconto que varia de $5 \%$ a $10 \%$. 
As ações de sustentabilidade do IPTU Verde de Salvador são organizadas em 5 categorias: Gestão Sustentável das Águas, Eficiência e Alternativas Energéticas, Projeto Sustentável, Bonificações, e Emissões de Gases do Efeito Estufa. Para exemplificar, destacam-se alguns critérios previstos no Decreto no $25.899 / 2015$ relacionados a: 1 . elementos construtivos ou estratégias para melhor aproveitamento climático das edificações: iluminação natural e ventilação das áreas de uso comum, fontes alternativas de energia, ventilação cruzada, previsão de dispositivos de proteção solar externos às aberturas dos ambientes, adoção de esquadrias externas com tratamento acústico, telhados de cobertura verde, entre outros; 2. incentivo à melhoria da ambiência de seu entorno: plantio de espécies vegetais nativas para sombreamento do passeio público, ampliação de área permeáveis além do exigido por Lei, dentre outros e 3. medidas que auxiliam na drenagem urbana: construção de reservatório e/ou valas de infiltração que permitam o retardo do escoamento das águas pluviais, aproveitamento de águas pluviais, utilização de pavimentação permeável, entre outros.

Com relação à aplicação do instituto tributário e financeiro - IPTU nos municípios avaliados, foi identificada a regulamentação do IPTU Verde nos municípios de São Carlos e Ribeirão Preto. O programa de incentivo de São Carlos é o menos abrangente, pois se restringe a dois critérios: existência de uma ou mais árvores na calçada de frente do imóvel e área interna efetivamente permeável com cobertura vegetal. Além disso, a referida lei restringe a aplicação do instituto a imóveis edificados horizontais. A lei de Ribeirão Preto é mais abrangente, pois inclui outras tipologias de imóveis (residenciais e não residenciais, horizontais e verticais), com previsão de maior quantidade de critérios, que envolve: plantio de árvores, sistema de captação de água da chuva e reuso de água, sistema de aquecimento solar (hidráulico e elétrico), uso de materiais sustentáveis, utilização de energia passiva e eólica, separação de resíduos sólidos.

Além do IPTU Verde, os municípios de São Carlos e Ribeirão Preto preveem na lei do Código de obras e edificações a coordenação entre elementos ou sistemas de sustentabilidade, exigidos ou facultados, que envolvem o uso de materiais sustentáveis, uso racional das águas, construção de reservatórios de detenção ou retenção, eficiência energética, dentre outros.

O município de Campinas, apesar de discutir entre os anos de 2018 e 2019 o projeto de lei para regulamentar o IPTU Verde, não avançou nesta política, tendo em vista o arquivamento da proposta em agosto de 2019. Neste sentido, o município possui um sistema de certificação 
regulamentado pela Lei complementar no 49/2013, que dispõe sobre o licenciamento ambiental de atividades e empreendimentos e pelo Decreto $n \div$ $18.705 / 2015$, que a regulamenta.

Conforme as normas, os empreendedores que adotarem as medidas de sustentabilidade (reciclagem interna dos resíduos, reuso e aproveitamento de água, utilização de tecnologias limpas, permeabilidade maior do que exigência legal incluindo o telhado verde, uso racional dos recursos naturais) obterão desconto nas taxas de licenciamento ambiental. No entanto, os que atenderem no mínimo 10 critérios relacionados a: redução na emissão de gases ou quantidade de efluentes gerados, uso de materiais sustentáveis, instalações prediais sustentáveis, reutilização/redução de matéria prima, criação ou apoio à implementação de unidade de conservação, dentre outros, farão jus ao Selo Sustentabilidade, que possibilita prioridade no licenciamento do próximo empreendimento da empresa, junto a Secretaria Municipal do Verde, Meio Ambiente e Desenvolvimento Sustentável. Este modelo de política adotado por Campinas restringe o interesse a grandes incorporadores, responsáveis por parte significativa da produção de empreendimentos na cidade.

Ao comparar as políticas de incentivo a sustentabilidade dos três municípios avaliados com o exemplo adotado neste trabalho, IPTU Verde de Salvador, nota-se que muitas ações ainda não foram contempladas, como: iluminação natural em escadas de segurança; iluminação natural e ventilação entre $50 \%$ a $100 \%$ das áreas de uso comum; ventilação cruzada; dispositivos de proteção solar externos às aberturas dos ambientes permitindo sombreamento; sistema de proteção e sombreamento de fachadas horizontais ou verticais, brises ou persianas externas, e outros protetores solares, ou ainda vegetação; apresentar níveis de eficiência envoltória de acordo com o RTQ-C; orientação ao sol e ventos, definido por estudos de insolação com soluções para sombreamento das edificações e melhor aproveitamento e estratégias de uso da ventilação natural e adoção de esquadrias externas com tratamento acústico. Dessa forma, avalia-se que estas legislações podem avançar muito no aprimoramento de ações que qualifiquem a produção arquitetônica, com proposição de edificações mais arrojadas em relação ao uso de materiais sustentáveis, elementos de sombreamento de fachadas e ambientes, melhor aproveitamento da ventilação natural, dentre outros, em busca da promoção de construções e cidades mais sustentáveis. 


\section{Considerações finais}

O presente trabalho demonstra uma crescente preocupação do poder público na gestão das cidades dentro dos princípios de sustentabilidade, em cumprimento às políticas, instrumentos e diretrizes preconizados pelo Estatuto da Cidade. Para os municípios avaliados, nota-se que as legislações são bem fundamentadas em princípios e diretrizes de base sustentável e direcionadas para a garantia da qualidade de vida urbana, garantia da proteção, preservação e recuperação das áreas ambientalmente frágeis, bem como para a promoção da função social da cidade e da propriedade. Foram identificadas, ainda, iniciativas de sustentabilidade, que envolvem critérios de permeabilidade urbana, de arborização e áreas verdes, de auxílio a drenagem urbana, de tratamento adequado aos resíduos sólidos, que contribuem não somente para melhoria no desempenho térmico dos ambientes abertos (públicos ou privados), bem como, das edificações.

A avaliação das legislações urbanísticas de São Carlos, Ribeirão Preto e Campinas demonstra que, apesar do porte diferenciado e das particularidades e desafios enfrentados por cada contexto urbano, o porte dos municípios pouco influenciou na execução de políticas de incentivo à sustentabilidade, uma vez que eles apresentam iniciativas semelhantes. Por outro lado, os exemplos de diferentes municípios brasileiros demonstram que a legislação urbanística conta com vários instrumentos que podem ser aplicados como política de incentivo a sustentabilidade, como o aprimoramento ou inovação dos parâmetros de controle urbanístico, que induzam ao projeto sustentável; o uso da Outorga Onerosa do Direito de Construir, previsto como instituto jurídico e político do Estatuto da Cidade, que pode ser aplicado para incentivar grandes empreendedores na adoção de ações de sustentabilidade em troca de potencial adicional construtivo; além do incentivo tributário e financeiro do IPTU Verde, que abrange edificações de variadas tipologias e usos, sendo possível prever uma maior gama de práticas de sustentabilidade edilícia, de forma análoga as certificações.

Assim, a pesquisa demonstra que há muito a avançar em termos de regulamentação de parâmetros de sustentabilidade de caráter mais edilício que urbanístico, seja no aprimoramento ou inovação dos parâmetros de controle urbanístico, no uso dos institutos previstos no Estatuto da Cidade, ou na regulamentação de ações de sustentabilidade de caráter mais edilício no escopo do IPTU Verde, com aplicação de medidas que promovam o 
melhor aproveitamento das condições de ventilação e iluminação natural, o uso de elementos de sombreamento, o uso de materiais sustentáveis e a melhoria no desempenho térmico das edificações, evidenciando a importância do papel do ambiente construído equilibrado na construção de uma cidade sustentável.

\section{Referências}

Azevedo, T. C. (2017). Tributação municipal como incentivo ao desenvolvimento sustentável nas cidades: o caso do IPTU Verde de Salvador (Tese de Doutorado). Pós-Graduação em Planejamento Territorial e Desenvolvimento Social, Universidade Católica do Salvador, Salvador, BA.

Belo Horizonte (1996). Lei n. 7.166 de 27 de agosto de 1996, Estabelece normas e condições para parcelamento, ocupação e uso do solo urbano do Município de Belo Horizonte. Recuperado: https://leismunicipais.com.br

Bitoun, J., \& Miranda, L. (org.). (2009). Tipologia das cidades brasileiras. Rio de Janeiro, RJ: Letra Capital, Observatório das Metrópoles.

Brasil (1966). Código Tributário Nacional. Recuperado em: http://www.planalto.gov.br

Brasil (1988) Constituição da República Federativa do Brasil, disponível em: http://www.planalto.gov.br (acesso em julho de 2019).

Brasil (2001). Lei no. 10.257 de 10 de julho de 2001. Estatuto da Cidade. Recuperado em: http://www.planalto.gov.br

Campinas (2018). Lei complementar no. 189, de 08 de janeiro de 2018. Plano Diretor Estratégico do Município de Campinas. Recuperado em: https://leismunicipais.com.br

Campinas (2018). Lei complementar no. 208, de 20 de dezembro de 2018. Lei de Parcelamento, Ocupação e Uso do Solo no Município de Campinas. Recuperado em: https://leismunicipais.com.br

Dantas, G. T. (2014). O IPTU Verde como instrumento de efetividade da função socioambiental da propriedade privada urbana (Dissertação de Mestrado). Faculdade de Direito, Universidade Federal da Bahia, Salvador, BA.

Feio, L. P. (2018). O IPTU Verde e a construção da cidade sustentável (Dissertação de Mestrado). Instituto de Ciências Jurídicas, Universidade Federal do Pará, Belém, PA.

Gaspar, A. D. S. (2018). Realidade e desafios para implementação de critérios de sustentabilidade nas edificações da UFRPE (Dissertação de Mestrado). Universidade Federal Rural de Pernambuco, Recife,PE.

IBGE (2008). Regiões de Influência das Cidades, Rio de Janeiro, RJ.

Júnior, N. S., \& Rolnik, R. (Coord.). (2001). Estatuto da Cidade: guia para implementação pelos municípios e cidadãos. São Paulo,SP: Instituto Pólis.

Ribeirão Preto (2007). Lei complementar no. 2.157, de 31 de janeiro de 2007. Parcelamento, Uso e Ocupação do Solo no Município de Ribeirão Preto. Recuperado em: http://www.ribeiraopreto.sp.gov.br

Ribeirão Preto (2018). Lei complementar no. 2.866, de 03 de maio de 2018. Revisão do Plano Diretor implantado pela Lei complementar no 501 de 1995. Recuperado em: https://www.ribeiraopreto.sp.gov.br

Ribeirão Preto (2019) Lei complementar no. 2.996, de 03 de outubro de 2019. Institui a concessão de benefício tributário por adoção de ações ecológicas no município de Ribeirão Preto - IPTU Verde. Recuperado em: https://leismunicipais.com.br

São Carlos (2005). Lei no. 13.692, de 25 de novembro de 2005. Define critérios para lançamento do Imposto Predial e Territorial Urbano, e dá outras providências. Recuperado em: http://www.saocarlos.sp.gov.br 
São Carlos (2008) Decreto no. 264, de 30 de maio de 2008. Regulamenta a aplicação dos incentivos ambientais. Recuperado em: http://www.saocarlos.sp.gov.br

São Carlos (2016). Lei no. 18.053, de 19 de dezembro de 2016. Plano Diretor do Município de São Carlos. Recuperado em: https://leismunicipais.com.br

Salvador (2013). Lei no. 8.474 de 02 de outubro de 2013. Altera dispositivos da Lei no 7.186 , de 27 de dezembro de 2006. Recuperado em https://leismunicipais.com.br

Salvador (2015). Decreto №. 25.899 de 24 de março de 2015, Institui o programa de certificação sustentável "IPTU verde". Recuperado em: https://leismunicipais.com.br

Schweigert, R. (2006). Plano diretor e sustentabilidade ambiental da cidade (Dissertação de Mestrado). Universidade Presbiteriana Mackenzie, São Paulo, SP.

Vitória (2018). Lei no. 9.271 de 22 de maio de 2018, Plano Diretor Urbano do Município de Vitória. Recuperado em: http://sistemas.vitoria.es.gov.br 